REGULAR ARTICLE

\title{
THE ALLEVIATION OF VITAMIN A DEFICIENCY THROUGH STAPLE FOOD FORTIFICATION IN GHANA
}

\author{
Shu WANG ${ }^{1}$, Wojciech J. FLORKOWSKI ${ }^{* 2}$, Manjeet S. CHINNAN ${ }^{3}$, Anna V.A. RESURRECCION ${ }^{3}$, \\ Daniel B. SARPONG ${ }^{4}$
}

\author{
Address: \\ ${ }^{1}$ University of Georgia, Department of Agricultural and Applied Economics, 305 Conner Hall, 147 Cedar Street, 30605 , \\ Athens, Georgia, \\ 2 University of Georgia, Department Agricultural and Applied Economics, 1109 Experiment Street, 30223-1797, \\ Griffin, Georgia \\ ${ }^{3}$ University of Georgia, Department of Food Science and Technology, 1109 Experiment Street, 30223-1797, Griffin, \\ Georgia, \\ ${ }^{4}$ University of Ghana-Legon, Agribusiness Management Department, Legon, Ghana \\ *Corresponding author email: wojciech@uga.edu
}

\begin{abstract}
This study focuses on the intake of vitamin A from staple foods that are or could be fortified using a survey conducted in three major cities in Ghana. The study distinguishes among consumption frequencies, i.e., daily, weekly, and monthly, of five staples (wheat and maize flour, groundnut oil, palm oil, and vegetable oil). A multivariate probit technique estimates three sets of five equations accounting for the consumption of five staples in three time periods (daily, weekly monthly). The correlations across equations were tested indicating the suitability of the selected estimation approach. The results suggest that per capita income, geographic location, employment status, education, and market access are important in determining consumption frequency. The results also reveal that the existing source of vitamin A from the food fortification program is insufficient for Ghanaian women to reach the WHO daily standard. Fortifying maize flour (in addition to already fortified vegetable oils and wheat flour), a staple, will largely alleviate the inadequate vitamin $\mathrm{A}$ intake among urban households.
\end{abstract}

Keywords: consumption frequency, multivariate probit, survey data, Ghana

JEL: Q19, Q18

\section{INTRODUCTION}

Countries in Africa face nutrition deficiencies resulting in premature death, disability, or reduced work ability. A conventional way of food fortification is through additives: specific nutrients added to food (WHO and FAO, 2000). As defined by WHO and FAO, fortification refers to "the practice of deliberately increasing the content of an essential micronutrient, i.e., vitamins and minerals (including trace elements) in a food irrespective of whether the nutrients are originally in the food before processing or not, so as to improve the nutritional quality of the food supply and to provide a public health benefit with minimal risk to health" (World Health Organization, 2009).

Major deficient nutrients among urban populations in Africa include vitamin A (Agble et al., 2009). The Vitamin A Supplementation Trials study (VAST) conducted over the period 1988-92 in the savannah zone of Ghana shows high prevalence (approximately 65\%) of vitamin A deficiency among children aged 6-59 months (Kirkwood et al., 1993). In addition, a 2003 Ghana demographic and health survey indicates that the prevalence of vitamin A deficiency in mothers during their pregnancy is $7.7 \%$ (GSS, NMIMR and O.R.C. Macro, 2004).
In response to the problem, the government of Ghana has developed a food fortification program. Ghana pioneered food fortification with iodized salt in West Africa in 1996. Since 2006, the Economic Community of West African States (ECOWAS) (of which Ghana is a member) called for food fortification throughout West Africa. All members of the Professional Association of Cooking Oil Industries of the West African Economic and Monetary Union (AIFO-UEMOA) now fortify edible oil with vitamin A (Sablah, Grant and Fiedler, 2013). It is estimated that $70 \%$ of the population has access to vitamin A fortified edible oil in the 15 countries of ECOWAS and sustainable fortification of cooking oil is now a reality in all West African Economic and Monetary Union (UEMOA) countries (Sablah, Grant and Fiedler, 2013). It has been confirmed that in Ghana, $75 \%$ of vegetable oil is adequately fortified (Nyumuah et al., 2012).

The National Food Fortification Alliance (NFFA), constituted in Ghana in 2003, designed the Food Fortification Project to fortify wheat flour and commercial vegetable oil to address the high levels of anemia and vitamin A deficiency in the country (Nyumuah et al., 2012). The standards (GS 809:2006, GS810: 2006, GS 811:2006, GS812: 2006, and GS 813:2006) have been developed by the Ghanaian government and have been in effect since 2006. From a practical standpoint, the 
regulatory standards do not consider the possible losses due to poor handling of fortified foods, such as vegetable oils. The capacity for monitoring the standards is limited and costly. Vegetable oil is the major carrier of vitamin A while wheat flour is fortified with several micronutrients. In addition, the Ghanaian government has established a vitamin A supplementation program for children under the age of five with the target being the protection of children with two annual doses of vitamin A (Agble et al., 2009). According to UNICEF, the first round achieved 50\% coverage in 2004 and $95 \%$ in the second round of the same year (UNICEF, 2015).

Countries often fortify wheat and maize flour as well as other staples such as cooking oil, sugar, or salt as part of their approach to address vitamin and mineral deficiencies (FFI, 2015). Though there are divergent standards regarding what to fortify across countries, vitamin A, vitamin B12, iron, folic acid, zinc, and niacin are among the most common micronutrients fortified in various food vehicles (Sablah, Grant and Fiedler, 2013). Vegetable oil and wheat flour are two major food vehicles fortified with additives in Ghana. Maize flour, while not fortified in Ghana, has been included in fortification programs in other African countries such as Kenya, Malawi, Mali, and Nigeria. What then, is affecting urban consumers' purchase and consumption of these fortified or potentially fortified staples? Earlier studies indicate that factors including household income, prices, consumer preferences, and education are important in the consumption of fruits and vegetables in sub-Saharan Africa (Ruel, Minot, and Smith, 2005). The socioeconomic and demographic factors that impact the consumption of staples are rarely studied.

The illustration of staple fortification in the current study is based on four selected foods: palm oil, groundnut oil, all other vegetable oil, and wheat flour. The potentially fortified staple, maize flour, is also considered. The urban population consumes less native grain than the rural population, while consuming more refined flours and oil and, therefore, is potentially more susceptible to micronutrient deficiency (Kyamuhangire et al., 2013). The fortification of staples, especially starches such as wheat and maize flours, is a way to reach low-resource households, which are the primary staple consumers and likely to be deficient in vitamin A. In order to examine the consumption frequency of the selected staples and the intake of vitamin A from staple sources, three consumption time periods are delineated: daily, weekly, and monthly. The focus on staples assures the capture of households regardless of their dietary diversity. A multivariate probit model is used to determine the probability of consuming each staple food category at each frequency level. Then, based on the consumption frequency of staples and assuming daily, weekly, and monthly amount of the consumed staple, vitamin A intake from the maize flour fortification is illustrated.

The efficacy of a fortification program focused primarily on selected vulnerable population segments, such as young women or small children, shows benefits. The impact of food fortification with vitamin A, vitamin B6, riboflavin, and zinc on breast-feeding women by comparing food records pre- and post-fortification was investigated in the Republic of South Africa (Papathakis and Pearson, 2012). The results show that there is a significant increase in mean dietary intake postfortification for all nutrients included in the national fortification program, but the majority of those tested still did not meet the nutrient intake standards (Papathakis and Pearson, 2012). A simulation method based on 24hour recall data has been applied to predict the adequacy of vitamin A intake among Cameroonian women and young children (Engle-Stone et al., 2014). They find that fortification programs would decrease the prevalence of inadequate intake to $35 \%$ among both women and children, but inadequate vitamin A intake would remain larger than $50 \%$ in the north of Cameroon, where vitamin A deficiency is most common, and increasing fortification in oil or another food vehicle for vitamin A is needed (Engle-Stone $\boldsymbol{e t}$ al., 2014). The current study examines the intake of vitamin A from vegetable oils and wheat flour using a different set of data, thus broadening the knowledge of staple food consumption in urban households in Ghana. The study also considers the effects of fortifying maize flour with vitamin $\mathrm{A}$ as a possible extension of the current fortification program. The fortification of maize flour in other countries positively affected children and adverse effects on adults were not found (Mildon et al., 2015).

Table 1 shows the required amount of nutrients according to Ghana's standards. The minimum level of vitamin $\mathrm{A}$, a focus of the study, was determined by setting a target of delivering at least $20 \%$ of the Estimated Average Requirement (EAR) (Allen et al., 2006). According to USDA, children 1-3 and 4-8 years of age are recommended to take 210 and $275 \mu \mathrm{g}$, respectively, of vitamin A daily. For female teenagers, the recommended daily intake is $420-485 \mu \mathrm{g}$, and for females in other age ranges, it is $500 \mu \mathrm{g} / \mathrm{d}$ (USDA, 2015).

Table 1. Volume of supplemented micronutrients in wheat flour and vegetable oil according to national standards.

\begin{tabular}{llr}
\hline Food category & Micronutrient & Amount $(\mathrm{mg} / \mathrm{kg})$ \\
\hline Wheat flour & Vitamin A & 2.00 \\
& Folic acid & 2.08 \\
& Vitamin B12 & 0.01 \\
& Thiamine & 8.40 \\
& Riboflavin & 4.50 \\
& Niacin & 59.00 \\
& Iron & 58.50 \\
& Zinc & 28.30 \\
Vegetable oil & Vitamin A & 10.00 \\
\hline
\end{tabular}

Source: Nyumuah et al., (2012).

\section{DATA AND METHODS}

\section{Data}

This study applies data collected through a survey implemented in three major cities in Ghana (Accra, Takoradi, and Tamale). The survey was carried out between February and June in 2011 and was first implemented in Tamale. Following the preparation of the survey instrument, the survey implementation started in 
the morning, and by the mid-afternoon, returning enumerators were debriefed, as that stage was considered a pre-test. To assure proper communication with potential respondents, Dagmoba-fluent enumerators were recruited from the workers of the Ghana National Statistical Service (GNSS) in the area, who were familiar with implementing surveys. The enumerators interviewed households selected from the sample of households used by the GNSS. The debriefing of enumerators and scrutinizing completed questionnaires did not reveal misunderstanding of posted questions. A total of 216 questionnaires were collected from Tamale households.

Similar implementation procedures were followed in Takoradi and Accra. Because of their coastal location, interviews were mostly held in English. In Takoradi, 230 households completed questionnaires, while 630 households were interviewed in Accra. The data were entered concurrently during the data collection by two assistants recruited from among the students at the University of Ghana at Legon.

The developed questionnaire contained a list of foods developed through a discussion with scientists from the University of Ghana and observations of daily diets. Respondents were asked about their consumption frequencies of certain foods or categories including vegetables, fruits, starchy staples, meats, dairy products, vegetable oils, animal fats, snacks, etc. The consumption frequency, referring to the respondent, was set at daily, weekly, and monthly intervals. The quantity of consumed foods implies the habitual volume that was not observed directly because of the data collection method and it is assumed that the same habitual volume was consumed with daily, weekly, or monthly frequency. That assumption is applied in the calculation of the vitamin A intake from maize flour later in this study. To assume consumption volume is not uncommon in studies about fortification; for example, per capita vegetable oil consumption was assumed at $2+/-1$ table spoons or $30+/-$ $15 \mathrm{~g}$ daily (Laillou et al., 2012).

In addition, the survey instrument included questions regarding age, gender, marital status, occupation, monthly food expenditure, and household composition regarding number of adults and number of children in various age ranges. The choices for respondent educational attainment included nine education categories ranging from lack of formal education to university and postgraduate degree. Respondents were also presented with a list of five options indicating their possible job status. Finally, locations indicating place of residency and market access information were also included in the survey.

The sample has 1076 observations in total, but incomplete observations such as a missing answer to a question are omitted. Also, seven male respondents were dropped to limit the respondent gender only to females, who are the primary food shoppers and meal preparers. Five households with exceptionally high monthly incomes were also deleted to ensure the Gaussian distribution of the income variable. Finally, respondents below twenty years of age were excluded for the same reason. The final number of observations in the sample is 954. Per capita income is calculated by adopting an OECD formula for converting household members of various ages into more uniform household size measures. The adopted OECD equivalent scale converts household members of various ages into a single measure by creating weights with each household member according to age. Accordingly, in this study the first adult of the household member is assigned a weight of 1 , each additional adult a weight of 0.7 , and each child a weight of 0.5 (OECD, 2015). Although other equivalent scales exist, none is recommended by OECD for general use (OECD, 2015). The Oxford method used to calculate per capita income is applied in the current study. It is reasonable to consider the "decreasing" effect in household resource needs if the number of household members is more than one person because the need for living materials, e.g., food, drink, space, energy, etc., will not increase proportionally as the number of family members increases, especially when the number of children is involved.

Table 2 shows descriptive statistics of the sample. The female respondents are on average 39.2 years old and three quarters of them are married. A typical household consists of, on average, two adults and two children. The average per capita income for respondents in the sample is 234.09 new cedis $(\$ 159.61$ at $\$ 1=1.4666$ (Trading Economics, 2018)), while the average monthly food expenditure is 58.35 new cedis $(\$ 39.79)$ in the month preceding the survey. With regard to education, $38 \%$ of the respondents have a university or higher degree and $13.4 \%$ have a secondary level degree. In terms of employment status, $24.3 \%$ are government employees and $64.2 \%$ are selfemployed.

In addition, two dummies account for job status: one for government employees and the second for the selfemployed. The latter is defined as one who grows his/her own foods or trades goods for a living in a Ghanaian context. Finally, respondents are grouped according to their education level (having university degree or secondary degree), while "other educational attainment levels" serve as the benchmark.

Of the 954 observations selected for the empirical analysis, $18.6 \%$ are from Tamale and $20.8 \%$ are from Takoradi with the rest collected from Accra-based households. The figures also show that only $17.9 \%$ of the respondents have access to supermarkets, almost $70 \%$ of the respondents have access to grocery stores, and $32 \%$ buy food at a street stand. Grocery stores vary in size, but are very small as compared to supermarkets, offer a limited variety of foods and non-food products, and the foods are placed on the counter by the store owner or a clerk.

\section{Consumption Frequencies of Targeted Foods and Food Categories}

Five food categories and their consumption with the daily, weekly, and monthly frequency are of particular interest in this study: palm oil, groundnut oil, all other vegetable oil, wheat flour, and maize flour. The first four are already included in the government fortification program, while the maize flour is a candidate for the food fortification program. The dependent variable is the self-reported consumption of a specific vegetable oil at a given frequency category; for example, the binary dependent 
variable assumes the volume of 0 if a respondent did not eat palm oil daily.

The Ghanaian diet largely relies on starchy roots represented by cassava and yams, fruit, such as plantain, and cereals, like maize and rice. The diversity of the diet remains low with starchy roots and cereals supplying almost three-quarters of the dietary energy (Agble $\boldsymbol{e t}$ al., 2009). The staple foods come in many traditional forms, such as fufu, comprised of cassava or yam; banku, consisting of maize flour; kenkey and tuozafi, both made from ground corn. Together with corn meal and bakery products, the indicated consumption frequency (daily, weekly, monthly) of staples extracted from the data records establishes the measure of maize flour and wheat flour consumption reflected in daily, weekly, and monthly frequencies.

Palm oil is an important ingredient in the diet of people in West Africa (Tagoe, Dickinson and Apetorgbor, 2012). In the sample, the percentages of respondents who consume palm oil daily, weekly, or monthly are $20.52 \%, 32.47 \%$, and $2.99 \%$, respectively (Table 3). The red-colored palm oil is processed from fruits of domestically grown palm trees (Tagoe, Dickinson and Apetorgbor, 2012). As a result, the oil is used in specific dishes in Ghanaian cuisine although its specified use varies from place to place. The reported consumption frequencies of urban female residents, who are the focus of the current study, contrast sharply with the results from Nti (2008), who conducted his study in the Manya Krobo District in the eastern region of Ghana (Nti, 2008). That study indicates the frequency of palm oil consumption at $66.5 \%, 31.3 \%$, and $2.0 \%$ for daily, weekly, and monthly time periods, respectively, for mothers of child-bearing age who had young children between the ages of 0 and 18 months in rural Ghana.

The percentages of respondents consuming groundnut oil are $8.56 \%, 15.36 \%$, and $4.33 \%$ in the three time periods, respectively. Groundnut oil is used in homes on a daily basis for the preparation of various meals (Teye, Teye and Odoi, 2011). Together with palm oil, ground nut oil is used in okro stew, eto, fante fante, red red, and egusi stew (Oniang, Mutuku and Malaba, 2003).

Several food items in the survey are grouped into a specific category. For example, corn oil, soy oil, sunflower oil, and "other vegetable oil" are combined into the category "Other oil". Although these vegetable oils are common in Ghana, the number of respondents who reported eating them is rather small. The aggregation is accomplished by creating a dummy for each food consumed at each consumption frequency level; namely, if any of the listed vegetable oils is reported as consumed daily, then the combination is coded as 1 , indicating daily consumption. For example, the variable "Other oil" is assigned a value of 1 if a respondent reported consuming any of the oils that constitute the "Other oil" category (i.e., sunflower oil, corn oil, soybean oil, or other vegetable oil), and a value of 0 if none of the other oils are consumed. The survey results confirmed that $17.11 \%, 19.59 \%$, and $6.5 \%$ of the respondents consume an oil included in the combined "Other oil" category with daily, weekly, and monthly frequency, respectively.

A similar approach has been adopted to combine the indicated corn meal, banku, kenkey, and tuozafi into a single category "maize flour" to account for corn-based products. Observed consumption shows that the cornbased product was consumed by $38.76 \%, 66.08 \%$, and $15.05 \%$ of urban respondents on a daily, weekly, and monthly frequency, respectively. The reported consumption of loaf bread, crackers, cereal, porridge, cakes, pudding, tart, and sweet doughnut create combined category "wheat flour". Similarly, wheat flour has an even higher share of consumers than the combined maize flour category.

Table 2. Descriptive statistics of variables included in the empirical model

\begin{tabular}{|c|c|c|c|}
\hline Variable name & Variable description / units of measurement & Mean & Std dev. \\
\hline & Demographic factors & & \\
\hline Married & $=1$ if a respondent is married & 0.753 & 0.431 \\
\hline Age & Actual age in years & 39.222 & 10.656 \\
\hline Household size & Number of household members $19-60$ years old & 2.319 & 1.195 \\
\hline Children number & $\begin{array}{l}\text { Number of household members between } 4-12 \text { years old } \\
\text { Socio-economic factors }\end{array}$ & 2.285 & 1.862 \\
\hline Per capita income & $\begin{array}{l}\text { Household income in the month preceding the survey / weighted by } \\
\text { the number of people in household, in cedis }\end{array}$ & 234.086 & 258.831 \\
\hline Spend & Monthly household expenditure on food, in cedis & 58.350 & 40.583 \\
\hline Employ_self & $=1$ if a respondent is self-employed & 0.642 & 0.480 \\
\hline Employ_gov & $=1$ if a respondent is gov/civil employee & 0.243 & 0.429 \\
\hline $\begin{array}{l}\text { Secondary } \\
\text { education }\end{array}$ & $\begin{array}{l}=1 \text { if a respondent has a secondary education (including Senior high/( } \\
\text { O-A level, Vocational school, Technical school, or Teacher training) }\end{array}$ & 0.382 & 0.486 \\
\hline College educated & $\begin{array}{l}=1 \text { if a respondent has a college education (including university } \\
\text { postgraduate) } \\
\text { Location }\end{array}$ & 0.134 & 0.340 \\
\hline Shop grocery store & $=1$ if a respondent has an access to the grocery store & 0.693 & 0.462 \\
\hline Shop street store & $=1$ if a respondent has an access to street stall & 0.321 & 0.467 \\
\hline Shop supermarket & $=1$ if a respondent has an access to supermarket & 0.179 & 0.383 \\
\hline Tamale & $=1$ if a household is in Tamale & 0.186 & 0.389 \\
\hline Takoradi & $=1$ if a household is in Takoradi & 0.208 & 0.406 \\
\hline
\end{tabular}


Table 3. Percentage of household's reporting consumption of five food categories with daily, weekly, and monthly frequency.

\begin{tabular}{llcrrrc}
\hline Food category & Daily & $\begin{array}{l}\text { Standard } \\
\text { error }\end{array}$ & Weekly & $\begin{array}{l}\text { Standard } \\
\text { error }\end{array}$ & Monthly & $\begin{array}{l}\text { Standard } \\
\text { error }\end{array}$ \\
\hline Groundnut oil & $8.56 \%$ & 0.28 & $15.36 \%$ & 0.36 & $4.33 \%$ & 0.20 \\
Palm oil & $20.52 \%$ & 0.40 & $32.47 \%$ & 0.47 & $2.99 \%$ & 0.17 \\
Other oil & $17.11 \%$ & 0.38 & $17.83 \%$ & 0.38 & $5.25 \%$ & 0.22 \\
Wheat flour & $60.93 \%$ & 0.49 & $14.95 \%$ & 0.36 & $18.25 \%$ & 0.39 \\
Maize flour & $38.76 \%$ & 0.49 & $42.47 \%$ & 0.49 & $8.66 \%$ & 0.28 \\
\hline
\end{tabular}

The percentage consuming wheat flour with daily, weekly, and monthly frequency is $60.93 \%, 50.41 \%$, and $22.06 \%$, respectively. The shares of households consuming wheat and maize flour confirm that both types of food are major staples in Ghana.

\section{Application of the Multivariate Probit Model}

A multivariate probit model is a set of probit equations that are estimated together, permitting an observed phenomenon to have multiple binary inter-dependent simultaneous outcomes (Greene and Hensher, 2009). These correlated choices often occur in a consumption as is the case in the current study. Multivariate probit is employed in the current study to estimate the consumption frequency of palm oil, groundnut oil, other vegetable oil, wheat flour, and maize flour. In the Ghanaian dietary culture, staple dishes are accompanied by a thick sauce and edible oil is an essential part of the sauce. Therefore, it is reasonable to assume the unobserved correlation in the error term of each equation in the model. Given the strong belief that the correlation between equations exists, the choice of multivariate probit model is viewed as highly appropriate.

Despite the popularity of the use of the discrete choice model in food consumption, the application of the multivariate probit model in consumption of staples such as oil and flour is rarely seen. Also, the estimation is expanded by incorporating three sets of regressions that further explain the determinants of consumption frequency for three different time periods, i.e., daily, weekly, and monthly.

\section{RESULTS AND DISCUSSION}

\section{Multivariate Probit Model Specification}

This study adopts a quintuple-variate probit model, with five outcome variables referring to consumption of palm oil, groundnut oil, "other vegetable oil", wheat flour, and maize flour. A group of explanatory variables includes demographic variables (respondents' marital status, age, number of children in a household, number of adults in a household), socio-economic variables (per capita income, monthly food expenditure per household), two employment status dummies, and two education level dummies. In addition, to control for location differences, three major cities are indicated by dummy variables with Accra serving as the benchmark. Three proxies indicate market accesses, i.e., access to grocery store, street stand, and supermarket. These proxies are in fact variables indicating where the respondents reported purchasing their food (an individual could purchase food in more than one type of outlet).

The choice of the multivariate probit model in this study relies on the significant correlation coefficients in the daily consumption model that confirms the cross equation correlation; i.e., the relation between consumption of palm oil, peanut oil, other vegetable oil, wheat flour, and maize flour daily are non-negligible. All cross equation correlation coefficients across five equations in the daily consumption frequency model are statistically significant. In the case of the weekly consumption frequency model, all correlation coefficients are significant except for one. It appears that the weekly consumption frequency of groundnut oil and other vegetable oil is not correlated. The number of statistically significant correlation coefficients in the monthly consumption frequency model is seven out of ten. The dependency of consumption of maize flour and palm oil, palm oil and groundnut oil, and maize flour and other vegetable oil has not been confirmed, but other correlation coefficients are confirmed to be significant. The multivariate probit approach is retained for the purpose of consistency.

Variable coefficients estimated using the multivariate probit are not directly interpretable as measures of changes induced in the dependent variable resulting from a change in explanatory variables (Green and Hensher, 2009). For the practical purpose of understanding the effectiveness of fortification of selected staples and development of recommendations for decision-makers, the estimated coefficients require an additional step of converting them into two types of effects, namely, marginal effects associated with a change in the continuous variable, and the effect of a change from 0 to 1 in the case of binary variables.

To calculate a partial effect for a dummy variable, for example, a variable depicting the marital status, employment, or education level of the respondent, the partial effect measures a change in probability of that variable equals 1 when the binary value changes from 0 to 1. Current practice favours averaging the individual marginal effects (Greene and Hensher, 2009). Therefore in this study, we evaluate the marginal effect by calculating the ME for every observation and then taking the average ME of all observations. The ME calculated in this study for each independent variable is conditioned on consuming all five categories at the same time. For example, the calculated marginal effect for variable "number of people in a household" is the change in the probability of consuming palm oil, peanut oil, "other 
vegetable oil", wheat flour, and maize flour altogether, while adding one more adult person to the household. The marginal effects are calculated using the "mvProbitMargEff" function in an "mvProbit" package written in $\mathrm{R}$ (Henningsen, 2015). The procedure bootstraps the data 500 times in order to obtain 500 MEs for each variable, and uses them to calculate the standard error for the ME. The change in probability of consumption frequency conditioned on five staples being consumed together within each of the three time periods by urban households in Ghana is discussed separately for demographic, socio-economic, and location factors.

\section{Conditional Marginal Effects \\ Demographic factors}

Married consumers are $19.8 \%$ less likely to consume daily all staple food categories considered in the current study as compared to non-married people (Table 4). These consumers are more likely to enjoy a wider variety of foods reflecting different food preferences and consequently are less dependent on consumption of the five staples considered in the model. Such differences between households of different marital status have to be considered when anticipating the effects of food fortification. It is possible the married respondents enjoy a wider variety of foods in general and the wide variety may be sufficient to assure adequate intake of nutrients.

Adding a person to a household increases the probability of eating all five staples within a month by $17.2 \%$ (Table 4). With that being said, policy makers may focus on large families to promote fortified staple consumption. However, small households and elderly consumers should not be neglected because they may be at risk of inadequate nutrient intake and would benefit from fortified foods.

\section{Socio-economic factors}

Consistent with expectations, rising per capita income significantly increases the probability of consuming all the considered food categories with daily frequency (Table 4). Providing targeted subsidies to low-income families will be more helpful as income rather than food expenditure significantly influences consumption frequency and frequency matters in eating fortified food. In this circumstance, providing food coupons or vouchers designated for the purchase of a specific fortified product would be more appropriate than cash supplements.

Having a university or secondary level degree increases the probability of consuming all five staples by $42.8 \%$ and $22.4 \%$, respectively, on a daily basis as compared to households of members with less or no formal education (Table 4). Similarly in the weekly consumption frequency model, having a university degree increases the probability of consumption of all staples by $42.1 \%$ (Table 4 ) as compared to the benchmark education category. These results further support the provision of information through community training programs to enhance the effectiveness of food fortification programs. Also, being self-employed increases the consumption of five staples by $40.8 \%$ (Table 4 ).

\section{Location}

Consumers who shop at a street stand have a $34.2 \%$ higher probability of consuming all five staples daily (Table 4). It appears that street stalls are potentially very important distribution channels of fortified foods if consumption of desired nutrients is to rise among urban households.

Table 4. Conditional marginal effect for daily, weekly, and monthly consumption frequency model.

\begin{tabular}{|c|c|c|c|c|c|c|}
\hline Variable name & $\begin{array}{l}\text { Conditional } \\
\text { marginal } \\
\text { effect for } \\
\text { daily } \\
\text { consumption }\end{array}$ & Standard error & $\begin{array}{l}\text { Conditional } \\
\text { marginal } \\
\text { effect for } \\
\text { weekly } \\
\text { consumption }\end{array}$ & Standard error & $\begin{array}{l}\text { Conditional } \\
\text { marginal } \\
\text { effect for } \\
\text { monthly } \\
\text { consumption }\end{array}$ & $\begin{array}{l}\text { Standarc } \\
\text { error }\end{array}$ \\
\hline \multicolumn{7}{|l|}{ Demographic factors } \\
\hline Children number & -0.028 & 0.031 & 0.034 & 0.029 & 0.054 & 0.034 \\
\hline Household size & 0.055 & 0.042 & 0.049 & 0.040 & $0.172 * * *$ & 0.045 \\
\hline Married & $-0.198 *$ & 0.117 & 0.086 & 0.117 & -0.076 & 0.164 \\
\hline Age & -0.001 & 0.005 & 0.002 & 0.005 & -0.003 & 0.006 \\
\hline \multicolumn{7}{|l|}{ Socio-economic factors } \\
\hline Employ_gov & 0.160 & 0.204 & 0.086 & 0.117 & -0.156 & 0.256 \\
\hline Employ_self & $0.408 * *$ & 0.183 & -0.062 & 0.188 & -0.076 & 0.216 \\
\hline Secondary education & $0.428 * *$ & 0.182 & $0.421 * *$ & 0.177 & -0.258 & 0.269 \\
\hline College educated & $0.224^{*}$ & 0.122 & 0.140 & 0.118 & -0.021 & 0.163 \\
\hline Per capita income & $0.001 * * *$ & 0.0002 & 0.0004 & 0.0002 & 0.002 & 0.002 \\
\hline Spend & -0.0004 & 0.001 & -0.001 & 0.001 & 0.0002 & 0.003 \\
\hline \multicolumn{7}{|l|}{ Location } \\
\hline Tamale & 0.230 & 0.135 & -0.111 & 0.141 & 0.230 & 0.135 \\
\hline Takoradi & -0.115 & 0.135 & -0.154 & 0.130 & $0.288 *$ & 0.170 \\
\hline Shop grocery store & 0.111 & 0.110 & $-0.309 * * *$ & 0.102 & 0.101 & 0.147 \\
\hline Shop street store & $0.342 * * *$ & 0.106 & -0.072 & 0.105 & 0.214 & 0.137 \\
\hline Shop supermarket & 0.600 & 0.130 & $0.252 * *$ & 0.122 & $0.376^{* *}$ & 0.158 \\
\hline
\end{tabular}

Notes: $* P<0 \bullet 10,{ }^{* *} P<0 \bullet 05,{ }^{* * *} P<0 \bullet 0$, respectively 
Table 5. Vitamin A intake from maize flour

\begin{tabular}{lllllll}
\hline $\begin{array}{l}\text { Daily } \\
\begin{array}{l}\text { consumption } \\
\text { level }(\mathrm{g})\end{array}\end{array}$ & $\begin{array}{l}\text { Vitamin } \\
\text { A } \\
\text { fortified } \\
(\mathrm{ppm})\end{array}$ & $\begin{array}{l}\text { Intake of } \\
\text { vitamin A } \\
(\mathrm{mg} / \mathrm{d})\end{array}$ & $\begin{array}{l}\text { Weighted } \\
\text { average daily } \\
\text { intake }(\mathrm{g})\end{array}$ & $\begin{array}{l}\text { Percentage of } \\
\text { recommendations } \\
\text { for male }(\%)\end{array}$ & $\begin{array}{l}\text { Percentage of } \\
\text { recommendation for } \\
\text { female }(\%)\end{array}$ & $\begin{array}{l}\text { Percentage of } \\
\text { recommendation for } \\
\text { children 4-8y }(\%)\end{array}$ \\
\hline 50 & 1.5 & 0.075 & 0.03386 & 5.42 & 6.78 & 12.31 \\
100 & 1.5 & 0.150 & 0.06774 & 10.84 & 13.55 & 24.63 \\
200 & 1.5 & 0.300 & 0.13548 & 21.68 & 27.10 & 49.27 \\
\hline
\end{tabular}

Similarly, a positive effect on weekly consumption frequency of five staples is observed for consumers who shop for food at supermarkets. With access to supermarkets, consumers are $25 \%$ more likely to consume all the listed staples weekly (Table 4). On the other hand, shopping at grocery stores decreases the probability of consuming the five foods weekly by $30.9 \%$ (Table 4). Moreover, consumers who report shopping for food at supermarkets have a $37.6 \%$ higher probability of eating all five staples within a month than those who do not shop at this type of retail outlet (Table 4).

With regard to the location of household and its effect on monthly consumption frequency, residents in Takoradi are $28.8 \%$ more likely to consume all considered foods as compared to residents of Accra (Table 4). Residents in a large capital city such as Accra likely have a wider variety of foods available and are less dependent on the five selected foods. The relevant practical question is whether such a decline in the probability of consuming fortified or potentially fortified foods threatens the adequate intake of the nutrients in question. Additional research may be necessary to provide the needed insights.

Additional Vitamin A Intake from Fortified Maize Flour Calculations are made for an anticipated additional amount of vitamin A intake from maize flour. Table 5 lists the estimated quantity consumed daily by an urban Ghanaian at three arbitrarily selected levels, namely 50g, $100 \mathrm{~g}$, and $200 \mathrm{~g}$. The listed fortification amount in maize flour is based on WHO recommendations (WHO, 2000). The product of figures in two columns is the estimated intake of vitamin A per person per day. The generalized results for the population as a whole are calculated by taking a weighted average daily vitamin A intake with the weights being the share of households that consume maize flour daily, weekly, and monthly as presented in Table 3. To be specific, the daily maize flour consumption by those respondents who are weekly consumers is the estimated daily quantity divided by 7 , while for the monthly consumers, the regular daily amount is divided by 30 . The far right column in Table 5 illustrates the percent of recommended daily intake for an adult male, female, and children between 4-8 years old by extrapolating the consumption frequency based on the survey data. If the average daily maize flour consumption per person is $50 \mathrm{~g}$, $100 \mathrm{~g}$, and $200 \mathrm{~g}$, respectively, the projected intake of vitamin $\mathrm{A}$ for males is $5.42 \%, 10.84 \%$, and $21.68 \%$; $6.78 \%, 13.55 \%$, and $27.1 \%$ for females; and for children between 4-8 years the percentages are $12.31 \%, 24.63 \%$, and $49.27 \%$. Therefore, if maize flour is fortified according to the WHO standard, and the population consumes on average $200 \mathrm{~g}$ of maize flour each day, maize flour will account for a substantial amount of the recommended vitamin A intake and, thus, mitigate vitamin A deficiency. The intent of this study is to show how to alleviate the deficiency. Complementary efforts may be necessary to assure adequate intake.

\section{CONCLUSIONS}

The multivariate probit model results reveal that while many social, economic, and demographic factors can explain the daily consumption of foods, their power vanishes as the consumption become more infrequent. As the time lapse gets longer (reported consumption is not daily, but weekly or monthly), many more factors are bound to effect eating behaviour. For daily consumption, the direction of the effects of marital status, number of children, and number of adults depends on the food category of interest. Generally, education, specifically a university level education, reduces the likelihood of consuming vegetable oil of any kind and flour on a daily basis, while monthly food expenditure and access to various markets increases the probability of consumption. However, those with a large monthly food budget are bound to consume less maize flour. Also, the regional location plays a big role in the amount of staple daily consumption. For weekly and monthly consumption, though the number of significant explanatory variables substantially decreases, the education level retains its potent effect, although the directional effect is unpredictable across food categories. In the case of maize flour, a higher level of education tends to reduce its consumption and if one has grocery store access, they are less likely to consider maize flour.

The consumer profile is essential for policy makers in efforts to fortify maize flour in addition to the existing fortification of wheat flour in Ghana. According to the results, the number of people in the household facilitates consumption, so a policy maker or manufacturer may target large-sized households and educate people about the link between health and nutrients in the products. In addition, food distribution can increase the consumption of maize flour by improving access to the product, especially in supermarkets and at street stands.

The study has several limitations. First, a larger number of observations could enhance results. Although the final sample has 954 data points, one reported consumption frequency for a specific food item within a certain time period is very low: only $8.56 \%$ of households report consuming groundnut oil daily. This small sample proportion causes problems when using the maximum likelihood estimation in the multivariate probit model such as an invertible correlation coefficient matrix. Further, 
since the current focus is on health issues, some proxies for health concerns could also be considered. The available data permits the use of smoking information to indicate health concerns, but due to the infrequent incidence of tobacco smoking, that proxy is omitted. However, caution should be exercised because the proxy could be representative of the underlying phenomenon. Lastly, we are developing consumer profiles to learn about consumer behaviour, existence of a niche market, and make suggestions about policy. It will also be more helpful if the exact amount of consumed foods is recorded as the intake of vitamins is directly related to the consumed amount. Researchers may conduct interviews or include open questions in the survey, and then apply the text mining technique and sentiment analysis to gain insights from the information. That approach offers additional knowledge about consumers and broadens program evaluation.

\section{Authors' statements}

The authors acknowledge financial support from Peanut Innovation and Mycotoxin Lab/USAID for the collection of the data used in this study through the grant "Enhancing the peanut value chain, from processing to marketing peanut and peanut products," USAID RF W-710-023.

The data was collected under the project focused on food consumption and shopping behaviour and was implemented by colleagues from the University of Ghana because of their experience of conducting multiple surveys for international organizations. Prior to interview with each respondent, enumerators presented the purpose of the survey and requested permission to conduct the interview assuring each respondent of confidentiality of individual's responses. Enumerators participated in earlier surveys and in some locations (Tamale) were working for the National Statistical Service. The survey instrument did not contain any information allowing the identification of a respondent. The respondent had the opportunity to terminate the interview at any moment. The nature of questions and the interview method was consistent with a food shopper survey and was not invasive.

\section{REFERENCES}

AGBLE, R., BADER, E., SOLAL-CÉLIGNY, A., PALMA, G. and DOP, M. C. (2009). Nutrition country profile for the Republic of Ghana. http://bases.bireme.br/cgibin/wxislind.exe/iah/online/?Isi $\underline{\mathrm{sScript}}=\mathrm{iah} / \mathrm{iah} . \mathrm{xis} \& \mathrm{src}=$ google \&base $=$ REPIDISCA\&lan $\mathrm{g}=\mathrm{p} \&$ nextAction=lnk\&exprSearch=180017\&indexSearc h=ID. Accessed March 2015.

ALLEN, L.H., BENOIST, B.D., DARY, O. and HURRELL, R. (2006). Guidelines on food fortification with micronutrients. http://www.who.int/iris/handle/10665/43412\#sthash.Lhq e45il.dpuf. Accessed March 2015

ENGLE-STONE, R., NANKAP, M., NDJEBAYI, A.O. BROWN, K.H. (2014). Simulations based on representative 24-h recall data predict region-specific differences in adequacy of vitamin A intake among Cameroonian women and young children following largescale fortification of vegetable oil and other potential food vehicles. $J \quad$ Nutr $144 \quad$ (11):1826-34. DOI: https://doi.org/10.3945/jn.114.195354

FOOD FORTIFICATION INITIATIVE (FFI) Available at:

http://www.ffinetwork.org/regional_activity/africa.php.

Accessed April 2015.

GSS, NMIMR and O.R.C. Macro (2004) Ghana Demographic and Health Survey 2003. http://www.dhsprogram.com/pubs/pdf/FR152/FR152.pdf Accessed March 2015.

KIRKWOOD, B.R, ARTHUR, P., ROSS, D.A., MORRIS, S.S., GYAPONG, J.O., and TOMKINS, A.M. (1993). Vitamin A supplementation in northern Ghana: effects on clinic attendance, hospital admissions and child mortality. The Lancet 342 (8862):7-12.

KYAMUHANGIRE, W., LUBOWA, A., KAAYA, A., KIKAFUNDA, J., HARVEY, P.W.J., RAMBELOSON, Z., DARY, O., DROR, D.K. and ALLEN, L.H. (2013). The importance of using food and nutrient intake data to identify appropriate vehicles and estimate potential benefits of food fortification in Uganda. Food and Nutr $\begin{array}{llll}\text { Bull } & 34 & \text { (2):131-42. }\end{array}$ https://doi.org/10.1177/156482651303400202

LAILLOU, A., HAFEZ, S.A., MAHMOUD, A.H., MANSOUR, M., ROHNER, F., FORTIN, S., BERGER, J., IBRAHIM, N. and MOENCH-PFANNER, R. (2012). Vegetable oil of poor quality is limiting the success of fortification with vitamin A in Egypt. Food and Nutr Bull 33 (3):186-93. DOI: https://doi.org/10.1177/156482651203300303

MILDON, A., KLAAS, N., O'LEARY, M. and YIANNAKIS, M. (2015). Can fortification be implemented in rural African communities where micronutrient deficiencies are greatest? Lessons from proje cts in Malawi, Tanzania, and Senegal. Food and Nutr Bull $36 \quad$ (1):3-13. DOI: https://doi.org/10.1177/156482651503600101

NTI, C.A. (2008). Household dietary practices and family nutritional status in rural Ghana. Nutrition Research and
Practice
2
(1):35-40
DOI:

https://doi.org/10.4162/nrp.2008.2.1.35

NYUMUAH, R.O., HOANG, T.C., AMOAFUL, E.F., AGBLE, R., MEYER, M., WIRTH, J.P., LOCATELLIROSSI, L. and PANAGIDES, D. (2012). Implementing large-scale food fortification in Ghana: Lessons learned. Food Nutr Bull 33 (Supplement 3):293S-300S. DOI: https://doi.org/10.1177/15648265120334S305

OECD (2015) Adjusting household incomes: equivalence scales. http://www.oecd.org/eco/growth/OECD-NoteEquivalenceScales.pdf Accessed March 2015

PAPATHAKIS, P.C. and PEARSON, K.E. (2012). Food fortification improves the intake of all fortified nutrients, but fails to meet the estimated dietary requirements for vitamins A and B 6, riboflavin and zinc, in lactating South African women. Public Health Nutr 15 (10):1810-17. doi: https://doi.org/10.1017/S1368980012003072

RUEL, M.T., MINOT, N. and SMITH, L. (2005). Patterns and determinants of fruits and vegetable consumption in sub-Saharan Africa: a multi-country comparison. Joint FAO and WHO workshop on fruit and vegetables for health.

http://www.who.int/dietphysicalactivity/publications/f\&v 
africa economics.pdf?ua=1. Accessed April 2015

SABLAH, M., GRANT, F. and FIEDLER, J.L. (2013). Food fortification in Africa, progress to date and priorities moving forward. Sight and Life 27(3): 18-24. http://www.sightandlife.org/fileadmin/data/Magazine/20 $13 / 27 \quad 3$ 2013/food fortification_in_africa.pdf

TAGOE, S.M.A., DICKINSON, M.J. and APETORGBOR, M.M. (2012). Factors influencing quality of palm oil produced at the cottage industry level in Ghana. Int Food Res J 19 (1):271-78.

TEYE, M., TEYE, G.A. and ODOI, F.N.A. (2011). Groundnut oil improves tenderness, juiciness and consistency of beef sausages. J Anim Feed Res 1 (5):16570 .

The United Nation Children's Fund (UNICEF) (2015). http://www.gainhealth.org/knowledge-

centre/project/ghana-universal-salt-iodization/. Accessed May 2015.
Trading Economics (2018). Ghanaian cedi 2007-2018.

https://tradingeconomics.com/ghana/currency. Accessed October 2018.

USDA (2015). National Nutrient Database for Standard Reference, Release 27, Software v.2.2.3. http://ndb.nal.usda.gov/ndb/foods/show/638?manu=\&fgc $\underline{\mathrm{d}}=$. Accessed March 2015

WHO and FAO Expert Committee on Food Additives. Evaluation of certain food additives and contaminants. World Health Organization technical report series 896:1$128 ; 2000$.

World Health Organization (2009). Vitamin A fortification of staple foods. http://www.who.int/elena/titles/vitamina_fortification/en/ Accessed March 2015 